\title{
Pig ear skin temperature and feed efficiency: Using the phase space to estimate thermoregulatory effort
}

\author{
José M. Requejo, Miguel Garrido-Izard, Eva C. Correa, Morris Villarroel, \\ Belén Diezma
}

\begin{abstract}
Mammalian skin temperature is often used as an indicator of health status but has also been used in animal production as a proxy measure for thermoregulatory effort or energy wastage. An animal with a higher skin temperature may also have a lower feed efficiency. With advances in technology it is now feasible to continuously record temperatures of livestock over protracted periods of time. In this study, the ear skin pig temperature was related to feed efficiency using phase space diagram methodology. Fourteen Landrace finishers (all male) housed in one pen over a week at relatively high temperatures (average temperature throughout the experiment $27^{\circ} \mathrm{C}$ ) were supervised. The date, time and amount of feed consumed per individual animals was monitored via an electronic feeding station. The number of visits to the feeding station was used as an indicator of physical locomotor activity. Each animal was weighed at the beginning and at the end of the experiment to calculate their feed efficiency. The areas of the phase space diagrams of skin temperatures were used to quantify the variability of the time temperature series. Two areas in the phase space were correlated with feed efficiency $(r=0.77)$ and physical locomotor activity $(r=0.53)$. An index was developed that includes both areas, which increased the correlation between the variability of ear skin temperature and feed efficiency to $r=0.85$. This methodology could be used to help categorise pigs in terms of feed efficiency for rapid phenotyping.
\end{abstract}




\begin{tabular}{ll} 
Nomenclature \\
A1 & $\begin{array}{l}\text { Phase space area covered by } 1 \% \text { furthest from } \\
\text { the centroid }\end{array}$ \\
A100 & Phase space area covered by 100\% \\
A61 & Phase space area covered by $61 \%$ furthest from \\
& the centroid \\
A95.5 & Phase space area covered by $95.5 \%$ furthest \\
& from the centroid \\
D & Dark \\
FE & Feed efficiency \\
Hi & High feed efficiency \\
IndA & Index based on phase space areas \\
IR & Infra-red \\
$\mathrm{k}$ & Time index \\
L & Light \\
Lo & Low feed efficiency \\
Mi & Middle feed efficiency \\
$\mathrm{n}$ & Number of recording samples \\
$\mathrm{N}$ & Phase space dimension \\
$\mathrm{r}$ & Correlation coefficient \\
$\mathrm{RFID}$ & Radio-frequency identification \\
$\mathrm{RH}$ & Relative humidity \\
$\mathrm{SD}$ & Standard deviation \\
$\mathrm{T}$ & Temperature \\
Td & Dry bulb temperature \\
$\mathrm{t}_{\mathrm{d}}$ & Time delays \\
$\mathrm{THI}$ & Temperature-humidity index \\
$\mathrm{Tw}$ & Wet bulb temperature \\
$\Delta$ & Phase space time step \\
$\tau$ & Data acquisition interval \\
& \\
\hline
\end{tabular}

\section{Introduction}

The skin temperature of mammals can be an indicator of health status since stressed or diseased states will tend to cause hyperthermia (Loughmiller et al., 2001), but less is known about the relationship between skin temperature and thermoregulatory effort or feed efficiency. Exercise, eating, and even psychological stress can cause short term hyperthermia, changing the thermoregulatory set-point under normal, non-disease conditions (Grant, 1950). In recent years, advances in technology have produced a growing number of electronic devices for farm animals that can provide more detailed data about diurnal variation in body temperature (Langer \& Fietz, 2014), including deep body implants, subcutaneous chips and infra-red (IR) thermographers (Soerensen \& Pedersen, 2015). Specifically, Andersen, Jørgensen, Dyblkær, and Jørgensen (2008) demonstrated for pigs that continuous monitoring of ear skin temperature using small data loggers can give indications of thermoregulatory effort.

Feed efficiency is one of the most important determinants of animal productivity. Animals with a higher deep body temperature will use more energy to produce metabolic heat, at the expense of productivity (Britt, Thomas, Speer, \& Hall, 2003; Herd \& Arthur, 2009). Lower physical activity associated with reduced energy expenditure improves efficiency in pigs (Meunier-Salaün et al., 2014). Labussière, Dubois, van Milgen, and Noblet (2013) found that partitioning heat production in growing pigs can help to calculate efficiency, where heat production includes physical activity, the thermal effect of feed and basal metabolism. In cows, one study attempted to relate skin temperature with residual feed intake (DiGiacomo et al., 2014), finding that more efficient cows have lower skin temperatures than inefficient ones. Skin temperature was measured with IR technology to calculate individual thermoregulatory ability, which in turn is related to feed efficiency, although the precision of the technique varies with environmental temperature.

The thermoregulatory response of animals is influenced by environmental conditions (Wathes et al., 1994), such that hot climates can seriously limit pig production and performance. The Ministry of Agriculture in Spain suggests that pigs be fattened at a temperature between 15 and $23^{\circ} \mathrm{C}(25-150 \mathrm{~kg}$ live weight). In southern Europe, hot and dry summers make it difficult to maintain this temperature in commercial feedlots (Lucas, Randall, \& Meneses, 2000). Several indexes have been defined that combine the effect of temperature and relative humidity, adjusted for pigs of different live weights (Lucas et al., 2000). More studies are needed that measure individual temperature continuously and simultaneously in large groups, in combination with environmental and production data, such as the number of visits to feeding stations (Casey, 2003).

Once skin temperature data has been generated, it has to be processed in order to provide real time information to farmers to help them make decisions about how to control the thermal environment. One approach is to study the time series of a variable using new tools, such as the chaotic analysis of time series and phase spaces (or phase graphs); its potential to display the behaviour of dynamic systems of temperature has been demonstrated (Correa et al., 2014; Jiménez-Ariza et al., 2014). To the best of our knowledge, this method is not being used extensively in pig production, although Villarroel, Barreiro, Kettlewell, Farish, and Mitchell (2011) demonstrated its usefulness as a measurement of heat stress during pig transport. In this study we analysed how the phase space of ear skin temperature is related to feed efficiency and growth.

\section{Materials and methods}

\subsection{Animals}

Between June 19th and 26th (2017), 14 Landrace finishers (all male) were monitored in one pen (15 $\mathrm{m}^{2}$; Fig. 1) on a breeding farm in Villatobas, Castilla-La Mancha, Spain $\left(39^{\circ} 54^{\prime} 02.7^{\prime \prime} \mathrm{N}\right.$ $\left.3^{\circ} 17^{\prime} 31.4^{\prime \prime} \mathrm{W}\right)$ belonging to Hendrix Genetics, Boxmeer, The Netherlands. The initial animal density was $56.6 \mathrm{~kg} \mathrm{~m}^{-2}$ Environmental temperature was controlled automatically by an air cooling system (RN 12, Exafan, Spain). Extractor fans removed the hot air from the boxes when the temperature reached a set point $\left(20^{\circ} \mathrm{C}+4.0^{\circ} \mathrm{C}\right)$; hot outside air was drawn through the cooling units (wet surface of cellulose pad) to reduce temperature and increase humidity in the pens. A specific temperature sensor to control the cooling system was located $2 \mathrm{~m}$ above the central point of the room (total of six 


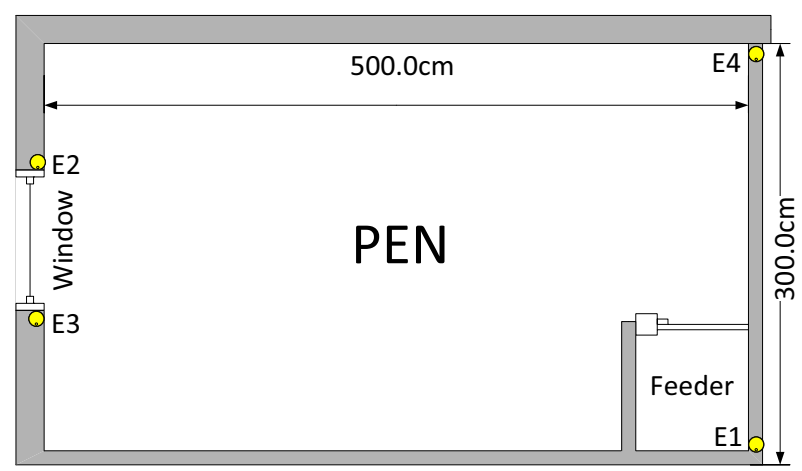

Fig. 1 - Design of the experimental pen which housed 14 pigs (full concrete slats), including one window and feeding station and the position of environmental sensors (temperature and humidity).

pens). The illumination schedule, according to the state of the room lights, was $14 \mathrm{~L}: 10 \mathrm{D}$, with day being from 7:00 to $21: 00$ and night from 21:00 to 07:00. All animals had access to two drinking nipples and one ad-libitum dry feed via an electronic feeding station (Compident MLP, Schauer Agrotronic GmbH, Austria), which weighed feed and residual trough feed. The feeder gates opened after identifying each pig by its unique radio-frequency identification (RFID) ear tag. Once the animal entered the station, the gates closed, the feed was weighed and placed in the trough, and after the pig left the station, the remaining feed was weighed. The date, time and amount of feed consumed per individual animal was stored so the total feed intake and occupation times per pig could be calculated. Overall the feeder was accessed 1268 times over one week. In addition, all pigs were weighed individually at the beginning and end of the trial to calculate feed efficiency (FE) as:

$\mathrm{FE}=\frac{\text { Final weight }(\mathrm{kg})-\text { Initial weight }(\mathrm{kg})}{\text { Cumulative feed intake }(\mathrm{kg})}$

\subsection{Temperature measurements}

To measure ear skin pig temperature, one iButton (DS1923, Dallas Semiconductor, USA) was glued to the RFID tag of each pig and placed on the inside half of the left ear. Four more identical iButtons (numbered E1 to E4) were placed around the pen at pig height (see Fig. 1) to measure environmental temperature and relative humidity (at a resolution of $0.0625^{\circ} \mathrm{C}$ and $0.04 \% \mathrm{RH}$, temperature range -20 to $+85^{\circ} \mathrm{C}$ and relative humidity range from 0 to $100 \%$ ). The environmental sensors were placed strategically to measure the variation in temperature and humidity throughout the pen at pig height. Ambient temperature and humidity were measured every $360 \mathrm{~s}$ while skin temperature was measured every $180 \mathrm{~s}$, due to limits of data storage $(n=1680$ readings for $\mathrm{T}$ and $\mathrm{RH}$ and $\mathrm{n}=3361$ readings for skin temperature). In order to calculate the temperature-humidity index (THI) Eq. (2) optimised for pigs from Lucas et al. (2000), was used where Td is dry bulb temperature and $\mathrm{Tw}$ is wet bulb temperature.

$\mathrm{THI}=0.63 \mathrm{~T}_{w}+1.17 \mathrm{~T}_{d}+32$

\subsection{Data analysis}

Descriptive statistics of environmental temperature and relative humidity ( $\mathrm{n}=1680$ data points from 4 sensors), skin temperature of the pigs ( $\mathrm{n}=3361$ from 14 sensors) and access to the feeding station $(n=1268)$ were calculated. Subsequently a phase space was constructed for each pig based on skin temperature data using time delays, following Eckmann and Ruelle (1985). A dynamic system can tend to move towards a nucleus, or attractor, and this can be seen clearly in a phase space representation. Each phase space was reconstructed in a phase graph using a time series versus itself delayed in time. The appropriate value for the time delays $t_{d}$ and system dimension $N$ was obtained by heuristics. In this work, the twodimensional $(N=2)$ phase space representations were obtained by plotting the measured temperature $T(k)$ at each time $\mathrm{T}(k)$ versus the temperature $\mathrm{T}(k+\Delta)$ at time $\mathrm{T}(k+\Delta)$, with an optimum step $\Delta$ established by heuristics. The data acquisition interval (i.e., the fixed time step of the time series) was $\tau$ $\min (3 \mathrm{~min}$ in this experiment), making the corresponding time delay $t_{\mathrm{d}}=\Delta \cdot \tau$ min. To obtain the optimum time delay, different values of $\Delta$ were tested systematically, looking for the maximum expansion of the trajectory loops or attractors in the phase space, retaining the points that could represent specific events. The area of the trajectory loops, corresponding to one sensor or group of sensors, was computed using the Matlab functions (MATLAB R2015b, MathWorks, Inc., Natick, MA, USA) convhull and polyarea. The convhull function allows to select a set of points from the trajectory loop in the phase space plot and returns the smallest convex envelope containing the set of points (vertices that define the polygon). The convhull function is based on the Quickhull (Qhull) algorithm for convex hulls (Barber, Dobkin, \& Huhdanpaa, 1996). The polyarea function returns the area of vertices defined by convhull. Correlations between different variables of interest were analysed using the statistical toolbox of Matlab® version 15.0.

From these phase space diagrams two variables of interest were extracted: 1) the centroid or centre of gravity $\left({ }^{\circ} \mathrm{C}\right)$ of the cloud of points that represents the arithmetic mean of all points of temperature registered, weighted by the local density of points or specific weight, and 2) the areas $\left({ }^{\circ} \mathrm{C}^{2}\right)$ that include all the points in the phase space as a measure of the total variability in temperature during the period (total area), as well as during the day and night. In addition to considering the area covered by all the points, we calculated the increasing areas on the phase space diagram starting from $1 \%$ of the points around the centroid to $100 \%$, in jumps of $0.5 \%(200$ areas in total).

Correlations among the variables recorded by the feeding station were calculated, including feed efficiency and all the areas on the phase space diagram for each sensor (pig). In that way the area that was most closely correlated with efficiency was identified. Correlations among locomotor activity indicators taken from the data from the feeding station and the phase space diagrams for each animal and period (13 animals x 14 periods) were also correlated. From the correlations obtained, an index based on the areas of the phase space, including those best correlated with efficiency as well as physical activity, was proposed. 
(a)

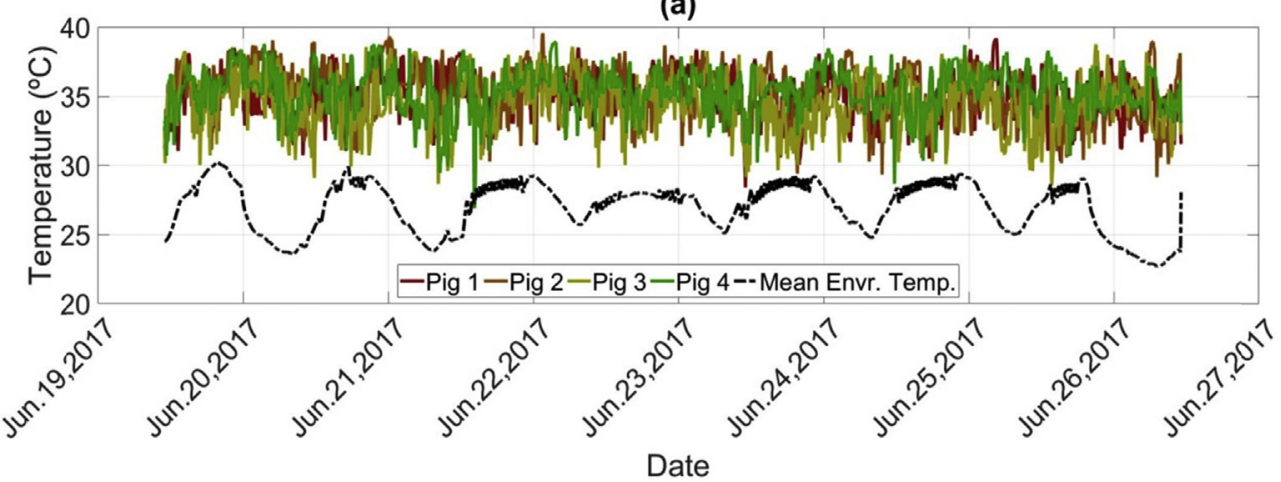

(b)

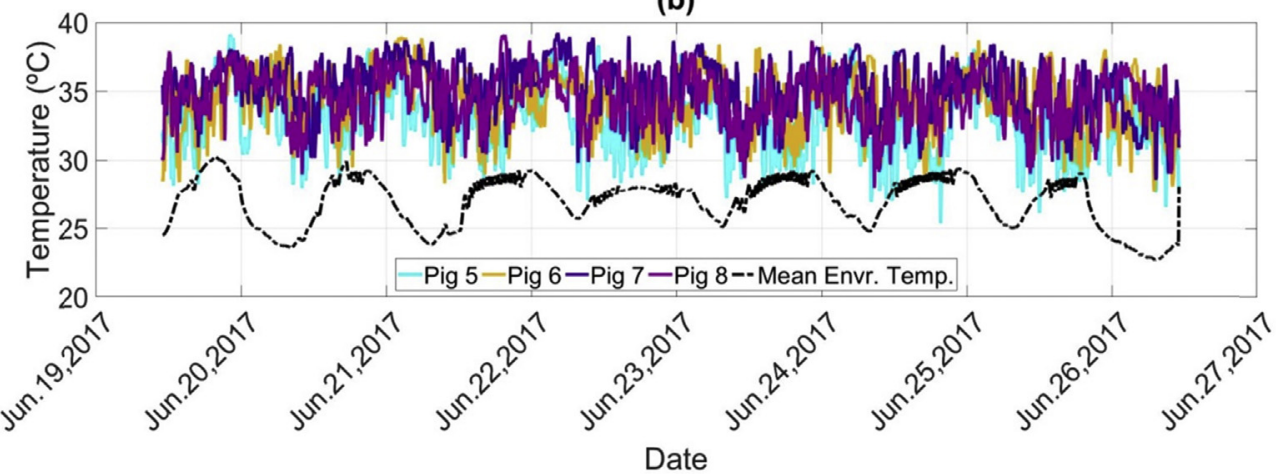

(c)

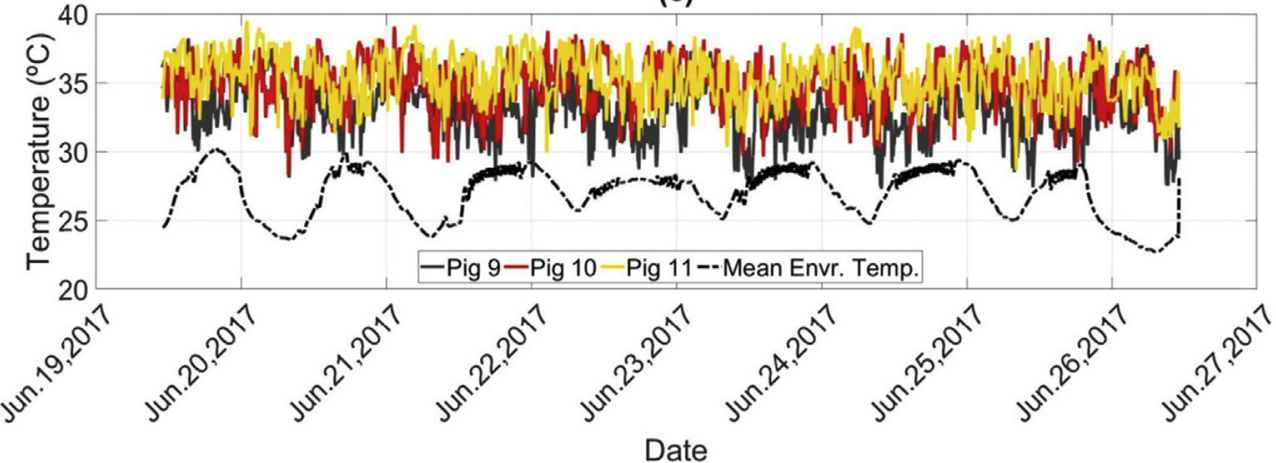

(d)

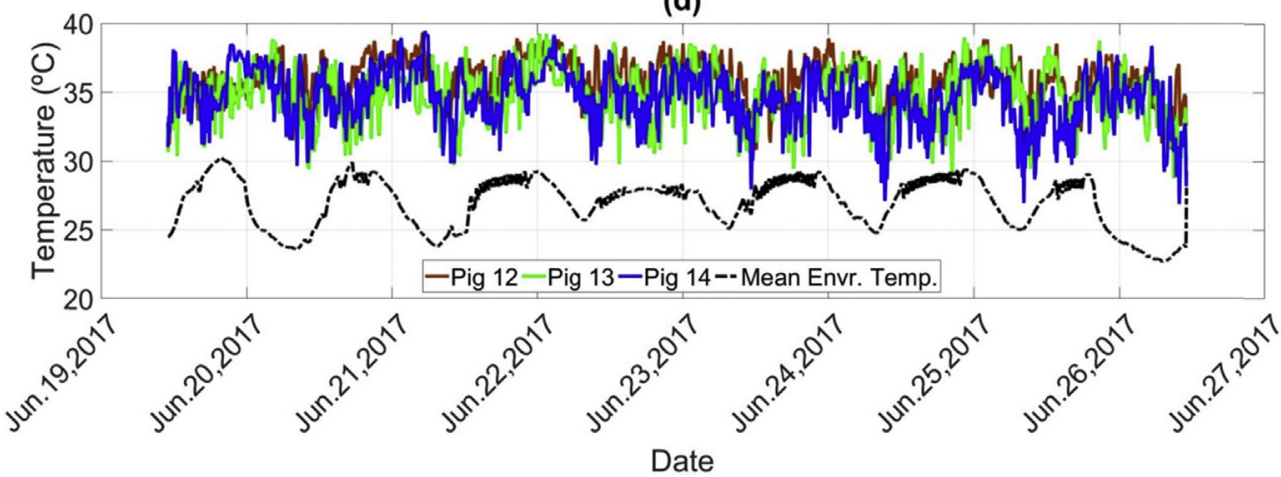

Fig. 2 - Time series of ear skin temperatures and average environmental temperature: (a) pig 1 to pig 4; (b) pig 5 to pig 8; (c) pig 9 to pig 11; and (d) pig 12 to pig 14. 


\section{Results and discussion}

\subsection{Environmental conditions}

The average temperature in the pen was $27 \pm 1.82{ }^{\circ} \mathrm{C}$ (range $21.16-30.74{ }^{\circ} \mathrm{C}$ ). The temperatures registered by the environmental iButtons were higher than the room set point, which can be explained by the differences in the location of these sensors and the sensor that controls the cooling system. The average relative humidity was $49.21 \pm 11.03 \%$ (range $24.06-80.11 \%$ ). Considering the average values of temperature and relative humidity, the value of the THI was 75.6, slightly over the alert limit. If we consider the standard deviations of temperature and relative humidity, the THI ranged from 74.0 (combination of $25.18{ }^{\circ} \mathrm{C}$ and $60.24 \% \mathrm{RH}$ ) to 77.0 (combination of $28.82{ }^{\circ} \mathrm{C}$ and $38.18 \%$ RH). In Fig. 2 the mean time series of environmental temperature was included, with higher temperatures during the day and frequent oscillations of high frequency that may have been due to the cooling system. Due to the location of the farm and the high thermal variation of the area, the temperature during the day was much higher and the cooling system was not able to maintain its set point.

\subsection{Feeding station}

Approximately $20 \%$ of all visits to the feeding station were very brief (less than $3 \mathrm{~s}$ ) and no food was ingested. The most amount of feed ingested in one visit was $963 \mathrm{~g}$ in $20 \mathrm{~min}$ (pig 3). At night, the feeding station was accessed $27.1( \pm 10.8)$ times per day, on average, compared to $154( \pm 37.2)$ times during the day, indicating that pigs fed more during the day. Based on the total feed ingested and the total weight gain per pig we calculated the FE per animal. We then used that value to group the pigs into three groups with significantly different $\mathrm{FE}$ values: low (Lo), middle (Mi) or high (Hi) (Table 1).

Table 1 - Productivity measures of the pigs under study $(\mathbf{n}=14)$, including initial weight, final weight, weight gain, cumulative feed intake and feed efficiency ( $\mathrm{kg}_{\text {gained }} \mathrm{kg}^{-1}$ ingested).

\begin{tabular}{lccccc}
$\begin{array}{l}\text { Initial weight } \\
(\mathrm{kg})\end{array}$ & $\begin{array}{c}\text { Final weight } \\
(\mathrm{kg})\end{array}$ & $\begin{array}{c}\text { Weight gain } \\
(\mathrm{kg})\end{array}$ & $\begin{array}{c}\text { Cumulative intake } \\
(\mathrm{kg})\end{array}$ & $\begin{array}{c}\text { Feed efficiency } \\
\left(\mathrm{kg} \mathrm{kg}^{-1}\right)\end{array}$ & $\begin{array}{c}\text { Group (Low, medium } \\
\text { or high FE) }\end{array}$ \\
\hline 65,60 & 71,00 & 5,4 & - & - & \\
64,00 & 65,00 & 1 & 12,218 & 0,082 & Lo1 \\
62,00 & 64,00 & 2 & 13,477 & 0,148 & Lo2 \\
61,20 & 64,00 & 2,8 & 16,175 & 0,173 & Lo3 \\
56,40 & 59,00 & 2,6 & 14,58 & 0,178 & Lo4 \\
56,30 & 58,90 & 2,6 & 12,719 & 0,204 & Mi1 \\
62,60 & 66,00 & 3,4 & 15,668 & 0,217 & Mi2 \\
64,30 & 68,00 & 3,7 & 16,643 & 0,222 & Mi3 \\
53,80 & 57,00 & 3,2 & 12,825 & 0,250 & Mi4 \\
56,70 & 61,00 & 4,3 & 15,014 & 0,286 & Mi5 \\
60,70 & 65,00 & 4,3 & 14,92 & 0,288 & Mi6 \\
61,50 & 66,00 & 4,5 & 15,052 & 0,299 & Mi7 \\
62,20 & 68,00 & 5,8 & 14,311 & 0,405 & Hi1 \\
61,60 & 68,00 & 6,4 & 14,882 & 0,430 & Hi2 \\
\hline
\end{tabular}

Table 2 - Area obtained by considering $100 \%$ of the data using a phase space representation and the areas obtained by separating the day and night data.

\begin{tabular}{|c|c|c|c|c|c|c|c|c|c|}
\hline \multirow{2}{*}{$\begin{array}{l}\text { Group (Lo; Mi } \\
\text { or Hi FE) }\end{array}$} & \multirow{2}{*}{$\begin{array}{l}\text { Centroid } \\
\left({ }^{\circ} \mathrm{C}\right)\end{array}$} & \multirow{2}{*}{$\begin{array}{c}\mathrm{SD} \\
\left( \pm^{\circ} \mathrm{C}\right)\end{array}$} & \multirow{2}{*}{$\begin{array}{l}\text { Area } \\
\left({ }^{\circ} \mathrm{C}^{2}\right)\end{array}$} & \multicolumn{2}{|c|}{ Day } & \multicolumn{2}{|c|}{ Night } & \multicolumn{2}{|c|}{ Day - Night ${ }^{\mathrm{b}}$} \\
\hline & & & & Centroid $\left({ }^{\circ} \mathrm{C}\right)$ & Area $\left({ }^{\circ} \mathrm{C}^{2}\right)$ & Centroid $\left({ }^{\circ} \mathrm{C}\right)$ & Area $\left({ }^{\circ} \mathrm{C}^{2}\right)$ & Centroid $\left({ }^{\circ} \mathrm{C}\right)$ & Area $\left({ }^{\circ} \mathrm{C}^{2}\right)$ \\
\hline & 35.1 & 1.61 & 65.29 & 34.8 & 32.91 & 35.7 & 21.73 & -0.94 & 11.18 \\
\hline Lo1 & 35.4 & 1.53 & 98.24 & 35.1 & 36.4 & 35.9 & 18.19 & -0.87 & 18.21 \\
\hline Lo2 & 35.3 & 1.92 & 81.7 & 34.8 & 42.36 & 36.2 & 17.61 & -1.37 & 24.75 \\
\hline Lo3 & 35.9 & 1.50 & 45.8 & 35.4 & 26.32 & 36.7 & 11.42 & -1.3 & 14.9 \\
\hline Lo4 & 34.5 & 1.87 & 80 & 34.0 & 44.22 & 35.3 & 25.45 & -1.28 & 18.77 \\
\hline Mi1 & 35.3 & 1.76 & 66.78 & 34.9 & 36.64 & 35.9 & 24.26 & -1.04 & 12.38 \\
\hline Mi2 & 33.1 & 1.92 & 80.62 & 32.5 & 40.73 & 34.1 & 27.91 & -1.64 & 12.82 \\
\hline Mi3 & 34.9 & 1.72 & 72.94 & 34.7 & 42.25 & 35.4 & 32.11 & -0.74 & 10.14 \\
\hline Mi4 & 34.7 & 1.99 & 92.56 & 34.0 & 44.07 & 35.8 & 20.1 & -1.8 & 23.9 \\
\hline Mi5 & 34.7 & 1.94 & 74.3 & 34.1 & 42.45 & 35.8 & 24.44 & -1.68 & 18.01 \\
\hline Mi6 & 35.4 & 1.71 & 69.6 & 35.1 & 32.6 & 35.9 & 33.92 & -0.8 & -1.32 \\
\hline Mi7 & 34.3 & 2.10 & 91.81 & 33.7 & 47.23 & 35.3 & 32.69 & -1.56 & 14.54 \\
\hline Hi1 & 32.8 & 2.29 & 112.3 & 31.9 & 55.86 & 34.2 & 35.84 & -2.27 & 20.02 \\
\hline $\mathrm{Hi} 2$ & 34.6 & 1.83 & 67.01 & 34.2 & 42.85 & 35.1 & 27.64 & -0.89 & 15.21 \\
\hline Avg. & 34.7 & 1.84 & 78.5 & 34.2 & 40.5 & 35.5 & 25.2 & -1.3 & 15.3 \\
\hline
\end{tabular}

${ }^{a}$ Coordinates $\mathrm{X}$ and $\mathrm{Y}$ for the centroid. Mean Temperature for each pig.

$\mathrm{b}$ Difference between day and night values. 
Unfortunately, for pig 1, the data from the feeding station were lost and could not be included. The average cumulative feed ingested was $14.5 \mathrm{~kg}( \pm 1.4 \mathrm{~kg})$ per pig and the average weight gain was $3.6 \mathrm{~kg}( \pm 1.5 \mathrm{~kg})$. The FE varied widely among pigs, from 0.08 to 0.43 (5.2 times greater).

\subsection{Pig skin temperature}

The average skin temperature (Table 2) was $34.70{ }^{\circ} \mathrm{C}$ (range from $32.82 \pm 2.29$ to $35.89 \pm 1.50{ }^{\circ} \mathrm{C}$ ). The average standard deviation $(n=3361)$ of the temperatures among animals as $1.75^{\circ} \mathrm{C}$. The average of the differences between the maximum and minimum temperatures was $6^{\circ} \mathrm{C}$. The difference in temperatures among animals was $12.2{ }^{\circ} \mathrm{C}$ maximum and $2.1{ }^{\circ} \mathrm{C}$ minimum. The time series of the skin temperatures is shown in Fig. 2. The average temperatures were higher at night and more variable during the day. No significant correlations were found between environmental conditions and pig skin temperature, with a maximum value of 0.23 and an average value of $0.07(+/-0.1)$ between each animal and the average environmental temperature.

\subsection{Phase space: variability in skin temperature}

The phase space in skin temperature of a high (Hi1) and a low (Lo3) pig are shown in Fig. 3 , with a 12 min time delay $\left(t_{d}=\right.$ $4(\Delta) \cdot 3 \min (\tau)=12 \mathrm{~min})$. In Fig. 3 the centroid of the data

(a)

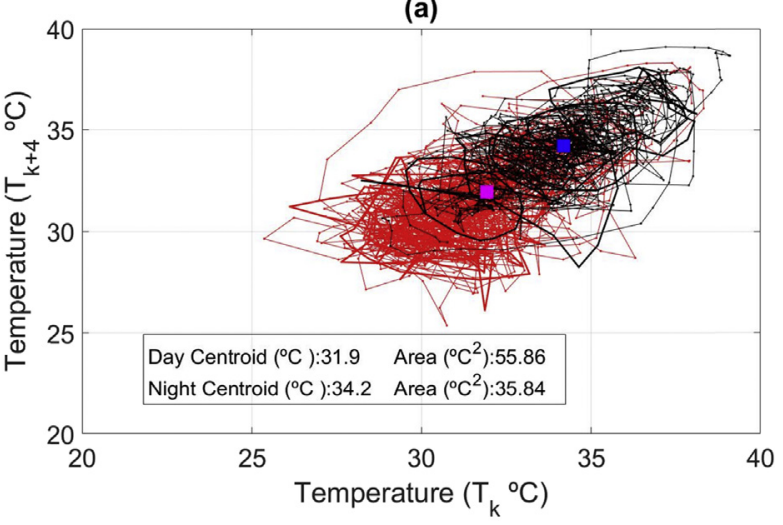

(b)

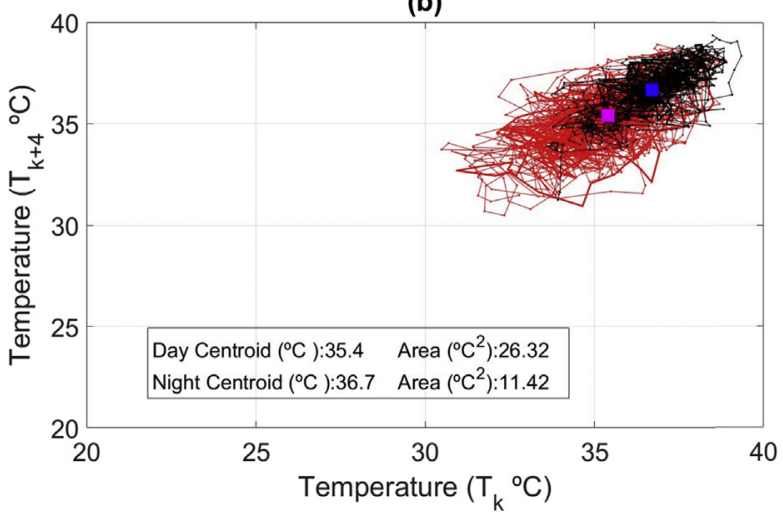

Fig. 3 - Phase space representation for all data $(100 \%$ percentile) separated by day (in red) and night (in black) of (a) one representative high and (b) low feed efficiency pig. registered during the day (red) and night (black) is presented. Table 2 summarises the $\mathrm{X}$ and $\mathrm{Y}$ coordinates of the centroids for each animal and period, as well as the areas.

During the day, the centroid of skin temperature was below the night centroid for all pigs, being $1.3^{\circ} \mathrm{C}\left( \pm 0.4{ }^{\circ} \mathrm{C}\right)$ lower

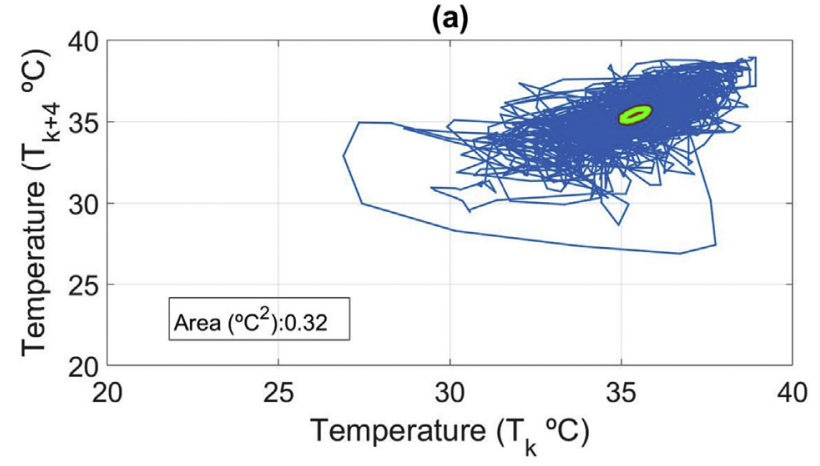

(b)

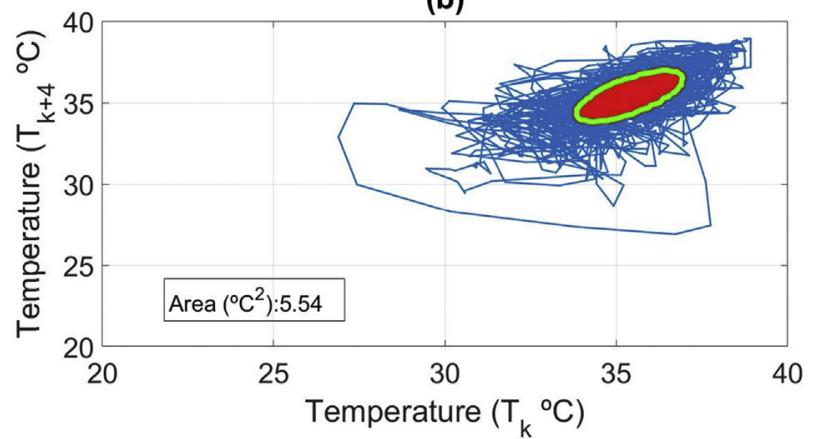

(c)

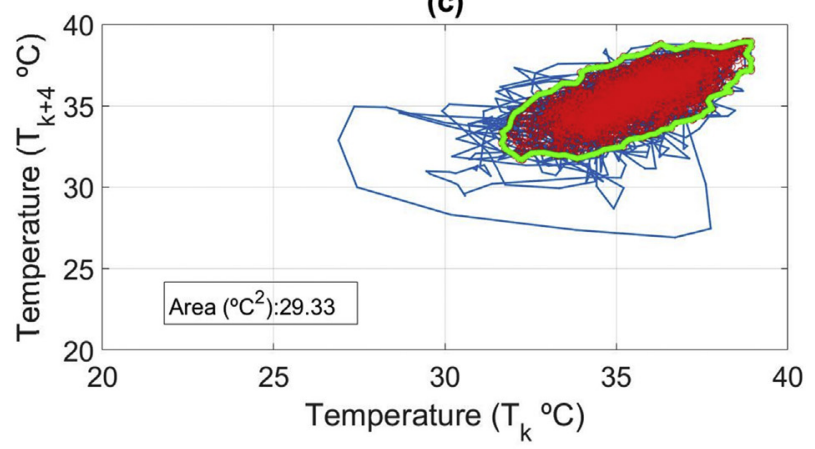

(d)

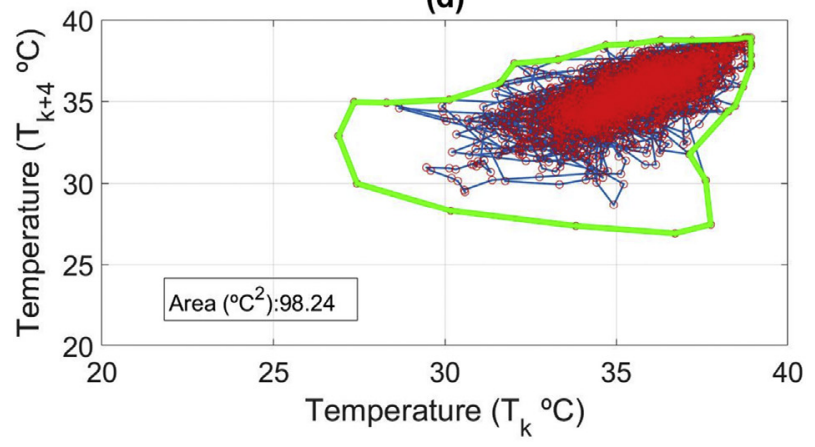

Fig. 4 - Areas of the phase spaces of one of the pigs with the percentage of points included: (a) $5 \%$; (b) $50 \%$; (c) $95 \%$; and (d) $100 \%$. Points included are represented in red, while border limit is represented by a green line. 
during the day. In contrast, the areas of the phase space diagrams during the day were $15.3^{\circ} \mathrm{C}^{2}\left( \pm 6.5^{\circ} \mathrm{C}^{2}\right)$ larger than during the night. Thus, the variability in skin temperature was higher during the day, which could be related to the cooling capacity of the cooling system and pig activity, which is higher during the day, as reported by Meunier-Salaün et al. (2014).

The difference in the phase spaces of skin temperature for high and low FE pigs is quite large. Figure 3 shows two representative animals. The data from the low FE pig are concentrated in the upper right corner, taking up less area than the high FE (pig 5). The centroid of the low FE pig is on average $3^{\circ} \mathrm{C}\left( \pm 0.5^{\circ} \mathrm{C}\right)$ higher (night and day) than high FE pig. The area is also $39.9 \%( \pm 7.7 \%)$ lower for low FE pig. Thus, the low FE pig maintained a higher and more stable skin temperature than the high FE pig.

Jiménez et al. (2014) showed how a phase space of time series can be useful to point out intense but short events. Those events generate large loops in the cloud of points of the phase space diagram, significantly increasing its area. For this reason, we calculated the area covered by $100 \%$ of the points (values shown in Table 2), as well as decreasing areas, to avoid including outliers. In Fig. 4 the phase space diagram of one pig is shown with 5, 50, 95 and $100 \%$ of all points. Note the threefold difference in area between considering $95 \%$ or $100 \%$ of the points furthest from the centroid. The key step is to find the percentage of points that provides valuable information, which is why we computed the phase space diagram for each pig from $1 \%$ (A1) to $100 \%$ (A100).

\subsection{Phase space: feed efficiency index}

A significant negative correlation was found between FE and skin temperature $(\mathrm{r}=-0.53)$ and a positive correlation with the standard deviation of skin temperature ( $r=0.6$, Fig. 5). There was also a significant positive correlation between the area of phase space A61 and FE ( $r=0.77$, Fig. $6 a)$. There were no other significant correlations between $\mathrm{FE}$ and the other variables measured from the feeding station (Fig. 5).

Given the high positive correlation between A61 and FE and the low value of the correlation coefficient $(r=-0.23)$ between that area and the indicator of physical locomotor activity (number of visits to the station), it was assumed that the dynamic system tends towards A61, which behaves like an attractor, and represents the maximum variability of the temperatures of the skin of each pig around the centroid associated with heat production under stable conditions. A larger area for A61 implies higher temperature variability and that the pig spent less energy thermoregulating, which increases FE.

Assuming that the points outside of the attractor (A61) in the phase space diagram are more related to locomotor activity, the upper limit of points (from A61 to A100) were compared with the number of visits to the feeding station (activity). Area A95.5 had the best correlation with the number of visits to the feeding station $(r=0.53)$, which indicates that $4.5 \%$ external points are very far from the centroid and are probably outliers. Using that information, an index was developed based on the areas of the phase space diagram,

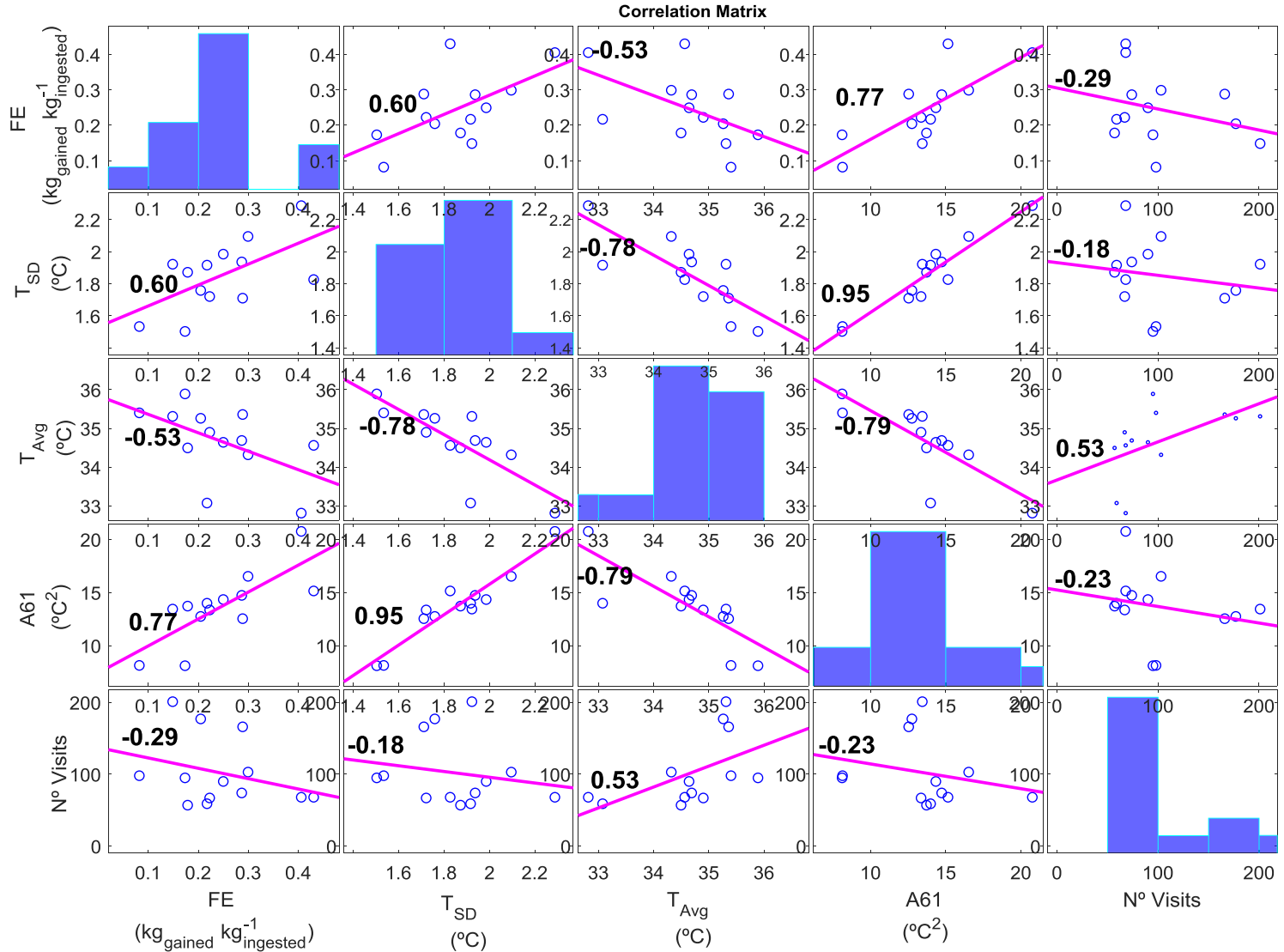

Fig. 5 - Correlations between FE and other variables studied: SD and average temperature, area A61 and number of visits to the feeding station. 


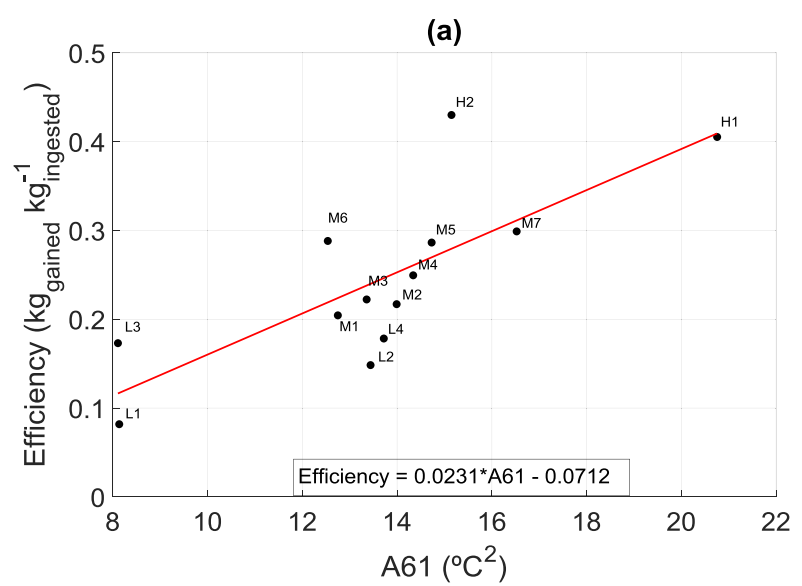

(b)

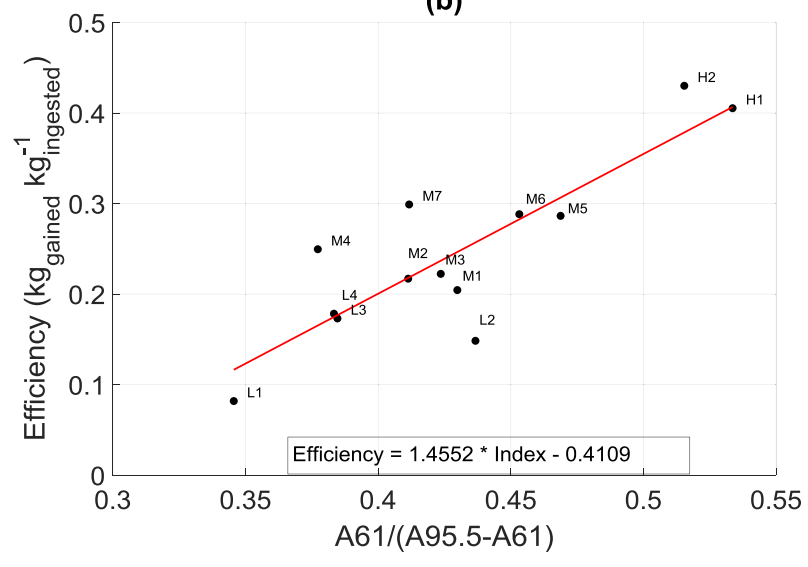

Fig. 6 - Linear fit and correlation between: (a) feed efficiency (FE) and area A61; and (b) FE and index IndA (A61/A95.5-A61).

starting from A61, which had shown better correlations with FE. Since A95.5 includes A61 and we are interested in the effect of locomotor activity on temperature data, the difference between the areas A95.5 and A61 was calculated, a difference that maintains the level of correlation with the number of visits. Then an index was defined: IndA $=$ A61/(A95.5-A61). Thus, higher A61 values that are related with higher FE and physical locomotor activity had a negative effect on FE, so that an increase in the difference between A61 and the area that includes the normal rate of activity should lower the FE.

In Fig. $6 \mathrm{~b}$, the relationship between FE and IndA $(r=0.85)$ is shown. There was an increase in the coefficient of correlation of areas with FE from 0.77 (considering only A61, Fig. 6a) to 0.85 by including A95.5, which indicates the relevance of combining the area related with thermoregulation with the area related with the physical locomotor activity.

The Eq. (3) of the linear fit between FE and IndA is:

$\mathrm{FE}=1.455 \cdot$ IndA -0.419

where FE is the feed efficiency ( $\mathrm{kg}_{\text {gained }} \mathrm{kg}^{-1}$ ingested $), 1.455$ is the

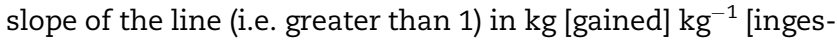
ted], and -0.419 is negative independent term (in $\mathrm{kg}$ gained $\mathrm{kg}^{-1}$ ingested). Thus, the average energy spent per $\mathrm{kg}$ of food ingested is at least $419 \mathrm{~g}$ of the basal metabolic activity. High values of IndA are reached for large A61 (greater variability in skin temperature) which implies less expenditure on thermoregulation, or a low level of locomotor activity, which corresponds with a low value for A95.5-A61. The combination of both effects can help to identify more efficient animals.

As shown in DiGiacomo et al. (2014), this study found that pigs with a lower average skin temperature were more efficient $(r=-0.53$ between efficiency and average ear skin temperature), but also that indicators of the variability in the temperature such as the SD $(r=0.6)$ and especially the phase space (A61 where $r=0.77$ ) were closely related. Taking into account that total heat production, as defined by Labussiere (2013) which includes physical activity, the thermal effects of ingestion and basal metabolism, our hypothesis is that different areas of the phase space include different components of heat production. Areas closer to the centroid (low percentage values) are more related with basal metabolism, and can be considered as more fundamental and stable aspects of animal physiology. As the area increases, the thermal effect of feeding and activity was incorporated.

\section{Conclusions}

Under the environmental conditions typical of summer in southern Europe, although slightly outside of the thermoneutral zone, a wide variety of skin temperature profiles in was found in pigs housed in the same pen and of the same genetic line. There was also a wide diversity in skin temperature (average and standard deviation of skin temperatures), feeding behaviour ( $\mathrm{g}$ ingested, number of visits), as wellweight gains (kg gained). All of this data could be used as a starting point to differentiate animals based on phenotype.

Applying the phase space methodology to the time series of ear skin temperature highlighted the variability among animals and periods of day and night. The quantification of this variability based on the areas computed in the phase space diagrams allowed to identify which areas were more correlated with feed efficiency $(r=0.77)$ and physical activity $(r=0.53)$. One index including both areas increased the correlation with feed efficiency to $r=0.85$.

For a breeding company, early identification of animals with high conversion efficiency is of great importance. Modern feeding stations allow continuous recording of individual weight and feed intake, which, together with ear skin temperature records, could help estimate feed efficiency throughout an animal's growth.

The results should be validated with more animals and over a whole production cycle, which could help to test whether the data extracted from the phase space diagrams are related with heat production components and the efficiency of energy use.

\section{Acknowledgment}

The funding of this work has been covered by Comunidad de Madrid and European Union through S2013/ABI-2747 (TAVSCM) and FEDER Innterconecta EXP 00082820/ITC-20151192 projects. 
sensors network. Food and Bioprocess Technology, 7(6), 1793-1806.

Labussière, E., Dubois, S., van Milgen, J., \& Noblet, J. (2013). Partitioning of heat production in growing pigs as a tool to improve the determination of efficiency of energy utilization. Frontiers in Physiology, 4.

Andersen, H. M. L., Jørgensen, E., Dybkjær, L., \& Jørgensen, B. (2008). The ear skin temperature as an indicator of the thermal comfort of pigs. Applied Animal Behaviour Science, 113(1), 43-56.

Barber, C. B., Dobkin, D. P., \& Huhdanpaa, H. (1996). The quickhull algorithm for convex hulls. ACM Transactions on Mathematical Software (TOMS), 22(4), 469-483.

Britt, J. S., Thomas, R. C., Speer, N. C., \& Hall, M. B. (2003). Efficiency of converting nutrient dry matter to milk in Holstein herds. Journal of Dairy Science, 86(11), 3796-3801.

Casey, D. S. (2003). The use of electronic feeders in genetic improvement programs for swine. PhD Diss. Ames: Iowa State Univ.

Correa, E. C., Jiménez-Ariza, T., Díaz-Barcos, V., Barreiro, P., Diezma, B., Oteros, R., et al. (2014). Advanced characterisation of a coffee fermenting tank by multi-distributed wireless sensors: Spatial interpolation and phase space graphs. Food and Bioprocess Technology, 7(11), 3166-3174.

DiGiacomo, K., Marett, L. C., Wales, W. J., Hayes, B. J., Dunshea, F. R., \& Leury, B. J. (2014). Thermoregulatory differences in lactating dairy cattle classed as efficient or inefficient based on residual feed intake. Animal Production Science, 54(10), 1877-1881.

Eckmann, J. P., \& Ruelle, D. (1985). Ergodic theory of chaos and strange attractors. Reviews of Modern Physics, 57(3), 617.

Grant, R. (1950). Emotional hypothermia in rabbits. American Journal of Physiology Legacy Content, 160(2), 285-290.

Herd, R. M., \& Arthur, P. F. (2009). Physiological basis for residual feed intake. Journal of Animal Science, 87(Suppl. 14), E64-E71.

Jiménez-Ariza, T., Correa, E. C., Diezma, B., Silveira, A. C., Zócalo, P., Arranz, F. J., et al. (2014). The phase space as a new representation of the dynamical behaviour of temperature and enthalpy in a reefer monitored with a multidistributed

Langer, F., \& Fietz, J. (2014). Ways to measure body temperature in the field. Journal of Thermal Biology, 42, 46-51.

Loughmiller, J. A., Spire, M. F., Dritz, S. S., Fenwick, B. W., Hosni, M. H., \& Hogge, S. B. (2001). Relationship between mean body surface temperature measured by use of infrared thermography and ambient temperature in clinically normal pigs and pigs inoculated with Actinobacillus pleuropneumoniae. American Journal of Veterinary Research, 62(5), 676-681.

Lucas, E. M., Randall, J. M., \& Meneses, J. F. (2000). Potential for evaporative cooling during heat stress periods in pig production in Portugal (Alentejo). Journal of Agricultural Engineering Research, 76(4), 363-371.

Meunier-Salaün, M. C., Guerin, C., Billon, Y., Sellier, P., Noblet, J., \& Gilbert, H. (2014). Divergent selection for residual feed intake in group-housed growing pigs: Characteristics of physical and behavioural activity according to line and sex. Animal, 8(11), 1898-1906.

Soerensen, D. D., \& Pedersen, L. J. (2015). Infrared skin temperature measurements for monitoring health in pigs: A review. Acta Veterinaria Scandinavica, 57(1), 5.

Villarroel, M., Barreiro, P., Kettlewell, P., Farish, M., \& Mitchell, M. (2011). Time derivatives in air temperature and enthalpy as non-invasive welfare indicators during long distance animal transport. Biosystems Engineering, 110(3), 253-260.

Wathes, C. M., \& Charles, D. R. (1994). Livestock housing. Wallingford (UK): CAB International, 1994. 